\title{
Eicosapentaenoic Acid
}

National Cancer Institute

\section{Source}

National Cancer Institute. Eicosapentaenoic Acid. NCI Thesaurus. Code C67080.

An essential, polyunsaturated, 20-carbon omega-3 fatty acid with anti-inflammatory and potential antineoplastic and chemopreventive activities. Eicosapentaenoic acid (EPA) may activate caspase 3, resulting in apoptosis in susceptible tumor cell populations. In addition, this agent may inhibit cyclooxygenase-2 (COX-2), resulting in inhibition of prostaglandin synthesis and prostaglandin-mediated inflammatory processes. 